\title{
Nossos Últimos 80 Anos
}

\author{
Our Last 80 Years
}

No dia 25 de janeiro desse ano, a Universidade de São Paulo comemorou os 80 anos de sua fundação. 80 anos se passaram desde que o então interventor do estado de São Paulo, Armando Salles de Oliveira, promoveu a união de escolas tradicionais, como a Faculdade de Direito do Largo São Francisco, a Escola Politécnica de São Paulo e a Faculdade de Medicina de São Paulo, em torno da recém-criada Faculdade de Filosofia, Ciências e Letras.

Desde então, a USP se tornou a maior universidade pública do Brasil, além de uma das maiores e mais prestigiosas da América Latina e do mundo. É, atualmente, responsável por mais da metade da produção científica do estado e por mais de um quarto do total da produção científica do Brasil. Conta com mais de 90 mil alunos matriculados, cerca de seis mil docentes e dezesseis mil funcionários, além de ser o maior centro de formação de mestres e doutores do mundo.

Trata-se de uma trajetória inegavelmente impressionante. Se, ao longo do século XX, o Brasil conquistou um lugar importante no mundo da produção de conhecimento, parte do mérito dessa conquista cabe à USP. Essa realização tão notável muitas vezes acaba trazendo consigo a pergunta: como foi que chegamos até aqui?

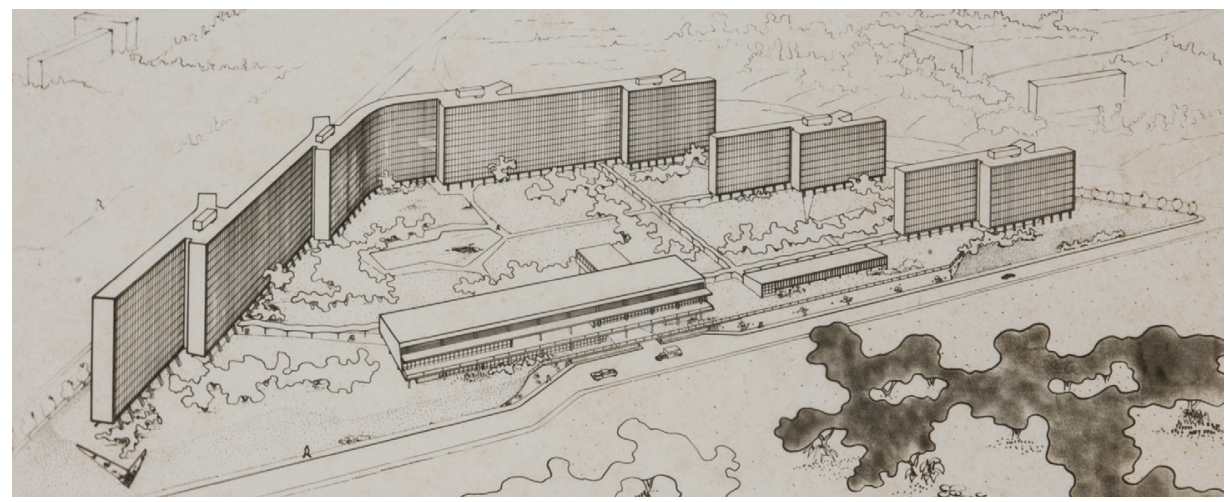

Rev. Cult. e Ext. USP, São Paulo, n. 11, p.29-36, maio 2014 DOI: http://dx.doi.org/10.11606/issn.2316-9060.v11i0p29-36
Gustavo Sumares

Universidade de São Paulo. Escola de Comunicações e Artes, São Paulo, Brasil

Figura 1 - Projeto para residência estudantil encontrado em caderno do arquiteto Rino Levi (Fonte: Arquivo da SEF-USP). 


\section{OS EDITAIS}

Essa foi uma das indagações que deu base à elaboração do Programa de Editais da Pró-Reitoria de Cultura e Extensão Universitária em 2012 e 2013. Em 2012, os editais ofereceram apoio financeiro a projetos voltados para a preservação, restauração e extroversão de acervos da Universidade, com o objetivo de valorizar adequadamente esses registros históricos. Também apoiaram projetos de valorização e preservação das memórias da USP, em todos os seus formatos. Estas linhas de financiamento visavam resgatar não apenas os documentos, mas também as lembranças e narrativas pessoais que fazem parte da história da Universidade.

Essas duas diretrizes de investimento, bem como uma terceira, voltada para o intercâmbio cultural e científico, foram mantidas em 2013, com algumas pequenas alterações. Ao longo dos dois anos, foram destinados cerca de 35 milhões de reais para projetos nessas linhas.

As propostas de financiamento foram delineadas por um grupo de trabalho composto por representantes de museus, institutos especializados e dos arquivos da USP, que compartilharam suas experiências em iniciativas semelhantes (do Ministério da Cultura e do Ministério de Ciência e Tecnologia, por exemplo), uma vez que não havia, dentro da USP, um acúmulo de experiências de fomento nesse formato.

Segundo o professor José Tavares Correa Lira, diretor do Centro de Preservação Cultural (CPC) - Casa da Dona Yayá - e um dos responsáveis pela elaboração dos editais, o retorno foi surpreendente: "Nós sabíamos que havia uma demanda em alguns lugares tradicionais de guarda, conservação e estudos desses acervos, como os grandes museus ou o arquivo central da Universidade", diz, "mas nós não sabíamos de uma enormidade de outras demandas que provinham de outros lugares menos conhecidos por seu interesse na preservação da memória e dos acervos da Universidade. Desde departamentos, laboratórios e setores de unidades, ou mesmo de órgãos da USP, até grupos de pesquisa, de estudantes e grêmios". Mais de 300 projetos das áreas de acervo e memória foram encaminhados ao longo dos dois anos dos editais, a maioria, segundo Lira, de ótima qualidade. Desse montante, 166 foram aprovados e estão em andamento.

Um dos frutos desse resgate da memória está à mostra no próprio $\mathrm{CPC}$, na forma da exposição $O$ Tempo das Construções. Ela resultou de uma parceria entre o CPC e a Superintendência do Espaço Físico (SEF-USP), e mostra projetos arquitetônicos, plantas, desenhos e fotografias de diversos símbolos arquitetônicos da Universidade, como as raias do

Figura 2 - Etapa final da construção do icônico edifício da Faculdade de Arquitetura e Urbanismo (FAU-USP). (Fonte: Arquivo da SEF-USP)

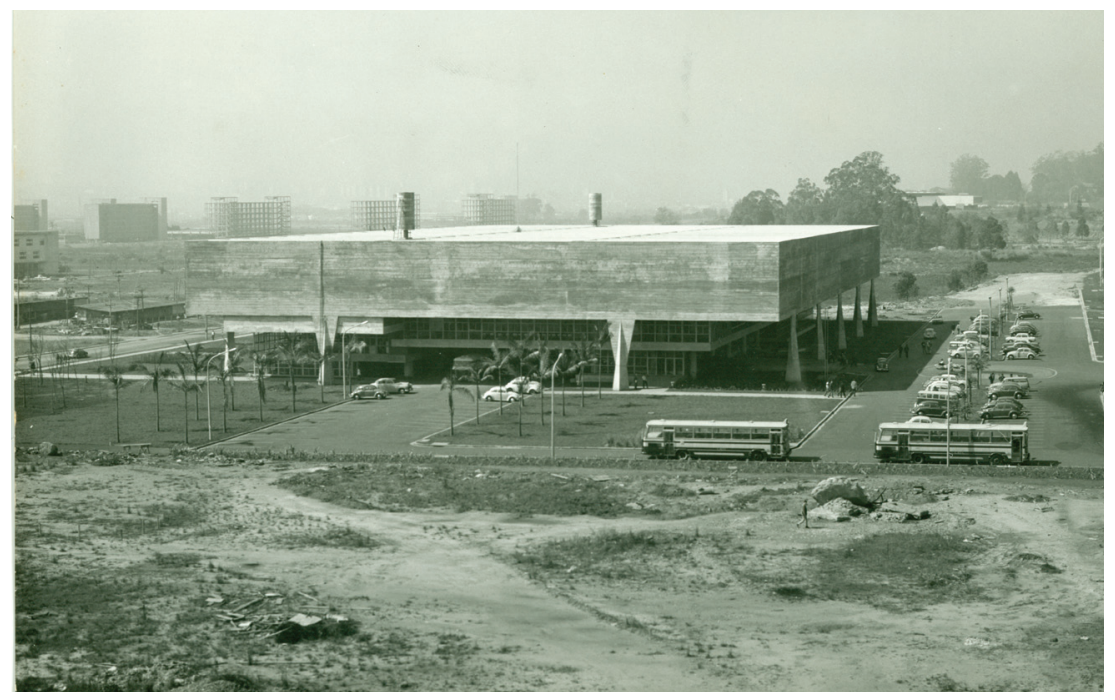




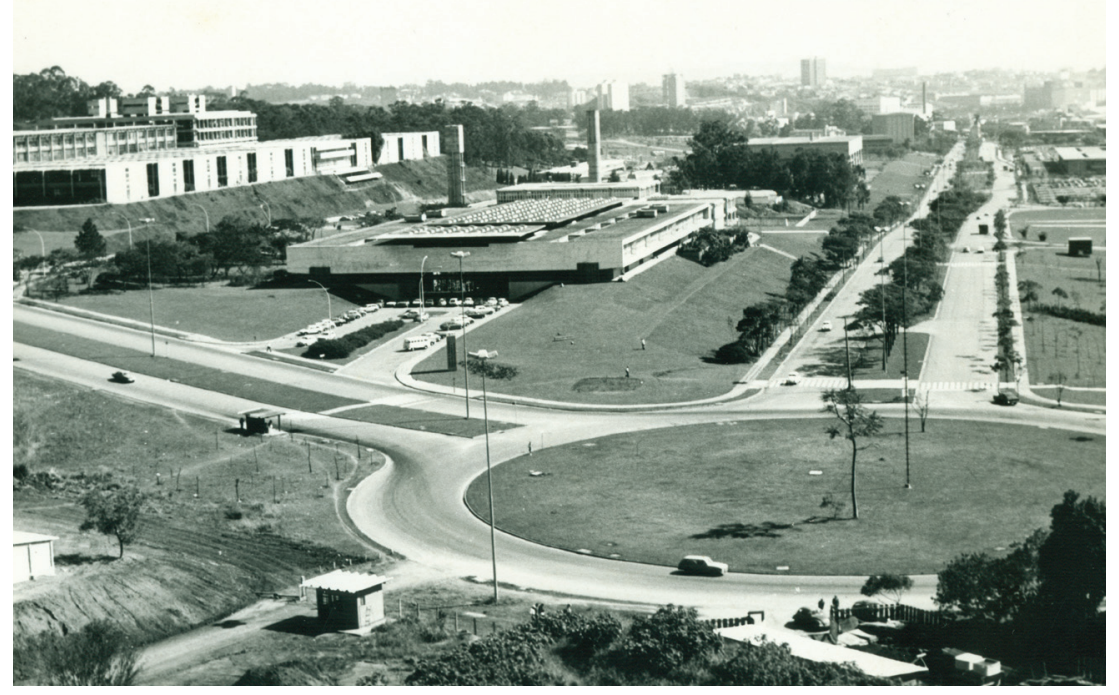

Figura 3 - Vista aérea da obra entregue do edifício de História e Geografia da Faculdade de Filosofia, Letras e Ciências Humanas (FFLCH-USP). (Fonte: Arquivo da SEF-USP)

Centro de Práticas Esportivas (CEPEUSP), a Faculdade de Arquitetura e Urbanismo (FAU-USP) e o edifício do Departamento de Geologia e Minas da Escola Politécnica (EP-USP). Por meio das imagens, é possível perceber as diversas relações que as pessoas que utilizaram esses locais estabeleceram com eles e visualizar como tais relações mudaram ao longo da história dos edifícios, desde seu planejamento, passando pela sua construção, até a sua ocupação.

Embora a Universidade já tenha, segundo o professor Lira, um histórico de valorizar sua história e investir nela, seja por iniciativas centrais, seja por iniciativas das próprias unidades, escolas ou departamentos, esses editais marcaram a primeira vez que uma iniciativa desse tipo "não se restringiu ao central nem ao setorial". "Ela visava sair das motivações imediatas ligadas às efemérides e comemorações do nascimento da Universidade" e "produzir não uma imagem única, oficial ou homogênea, mas abrir espaço para que distintos setores, áreas de conhecimento e experiências da Universidade pudessem se fazer presentes, olhando para o seu passado", diz.

\section{SUPORTES DA MEMÓRIA}

Uma olhada rápida pela lista de projetos aprovados nos editais revela uma enorme variedade de iniciativas, de diversas instituições e unidades da USP, que têm em comum a preocupação em valorizar e proteger não apenas a memória da Universidade, mas a ampla gama de trajetórias pessoais que compõem essa história.

Revela também que, frequentemente, essas trajetórias estão gravadas em suportes, aos quais não costumamos dar o nome de "patrimônio universitário". Os diversos documentos que professores aposentados deixam em suas gavetas, por exemplo: sob coordenação da especialista em laboratório Lilian Miranda Bezerra, do Arquivo Geral da USP (órgão central do Sistema de Arquivos da USP), esses papéis dispersos foram objeto de um projeto contemplado pelos editais de 2012.

O projeto coordenado por Lilian, Por uma política de preservação da memória da docência e da pesquisa na USP, mapeou parte dos acervos pessoais de docentes já desligados da Universidade, que atualmente não têm destino certo. $\mathrm{O}$ objetivo final do projeto, porém, era sensibilizar a comunidade universitária para a importância desse material.

"Quando um professor da faculdade se aposenta ou vem a falecer, muitas vezes ele deixa para trás uma grande quantidade de anotações sobre pesquisas ou sobre aulas que ele deu ou daria, que muitas 
Figura 4 - Vista aérea dos edifícios dos Departamentos de Engenharia Mecânica e Naval da Escola Politécnica (EP-USP). (Fonte: Arquivo da SEF-USP)

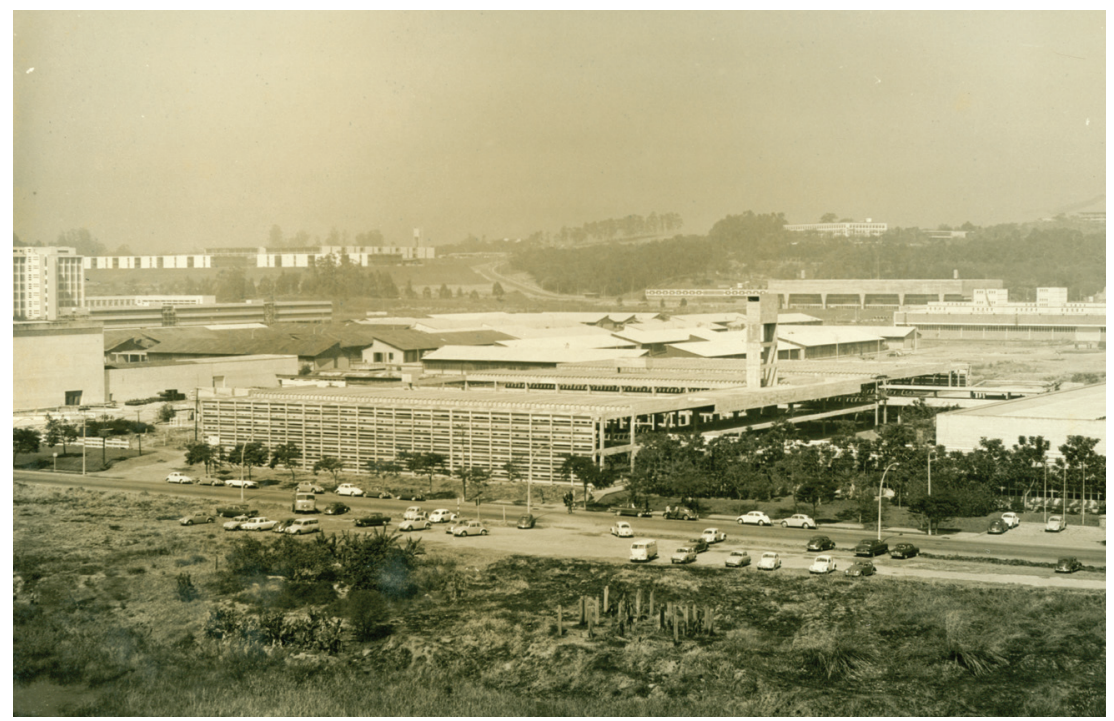

vezes contêm ideias valiosas. E, atualmente, a USP não tem uma política de preservação desse material, embora ele tenha tudo a ver com a atividade-fim da Universidade", explica.

Nesse trabalho, ela e um grupo de apoio composto por um aluno de mestrado e um grupo de estagiários realizaram mais de 200 visitas a 26 das 42 unidades da USP com a finalidade de explorar o que restou desses acervos. Essa realização só foi possível graças à colaboração das unidades e ao apoio dos trabalhadores do Arquivo Geral da USP, da chefe técnica de divisão Bárbara Julia Menezello Leitão e da consultora Johanna Wilhelmina Smit.

O projeto tinha a intenção de mapear esses arquivos pessoais de docentes e fornecer informações sobre sua localização, primeiramente para fins de pesquisa: pesquisadores que tivessem interesse no acervo de determinado professor, por conta de seu trabalho em certa área de pesquisa, teriam então conhecimento da existência desses documentos e, eventualmente, acesso a eles.

Geralmente, segundo Lilian, os "papéis" dos professores que não têm mais vínculo com a faculdade acabam ficando nas mãos dos professores que dividem a sala com eles e que acabam preservando esse material, seja porque acreditam em sua relevância acadêmica, seja por valorizar as lembranças que eles trazem. Ainda assim, segundo ela, essa política informal que relega aos colegas ou vizinhos de sala os apontamentos dos docentes desvinculados representa um destino bastante incerto para um material valioso.

"Foi muito comum ouvirmos respostas como 'Nós guardamos por um tempo, mas acabou se perdendo' ou 'Se vocês tivessem vindo ano passado, estaria tudo aqui', conta Lilian. Boa parte dos arquivos que ela encontrou estava dispersa por diversas salas e departamentos das unidades. Embora já existam na USP algumas iniciativas de preservação sistemática de acervos desse tipo, como a do Centro de Apoio à Pesquisa em História Sérgio Buarque de Holanda (CAPH) da Faculdade de Filosofia, Letras e Ciências Humanas (FFLCH-USP), "a dispersão é a regra”, afirma Lilian. "Os professores da USP fazem parte da ciência brasileira. Então não é a USP apenas quem perde, mas a ciência brasileira como um todo".

Para Lilian, o trabalho de campo revelou uma peculiaridade interessante desses arquivos: a mistura entre as esferas pessoal e profissional. Era bastante frequente que se encontrassem, em meio aos cadernos, anotações e preparações de aula dos professores, escritos de âmbito pessoal.

Segundo ela, a primeira experiência marcante do projeto ocorreu durante uma visita ao Instituto de Biociências (IB). Em uma sala um tanto bagunçada, 


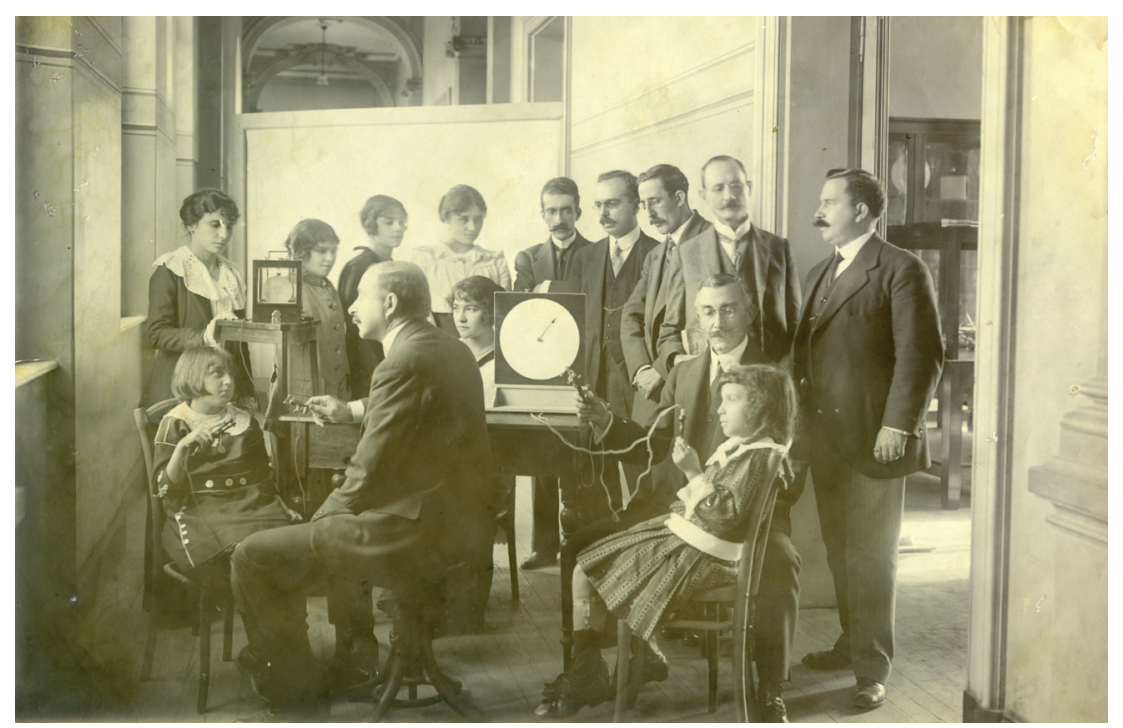

Figura 5 - Professores do Laboratório de Pedagogia Experimental utilizavam os Chronoscópios de D'Arsonval e Pizzioli para medir os tempos de reações a estímulos visuais (à esquerda) e táteis (à direita). (Fonte: Centro de Memória do Instituto de Psicologia)

o grupo encontrou, em meio a muitos outros documentos, um material riquíssimo do professor Crodowaldo Pavan, que lecionou na Universidade entre os anos de 1942 e 1978. O professor Carlos Vilela do IB, que ficou com a guarda desses materiais, deu ao grupo total liberdade para inspecioná-los. Entre os documentos, encontraram cadernos do professor Pavan com anotações diversas, relatos de viagens e até mesmo um caderno de espiral muito antigo com apontamentos sobre matemática, e poesias nas páginas finais, que pareceu ao grupo ser da adolescência dele, por seu tamanho menor e seu conteúdo diferente.

$\mathrm{Na}$ avaliação de Lilian, "é necessário que haja uma ação articulada da USP” no sentido de estabelecer uma política de preservação de acervos dessa categoria. Com as comemorações dos 80 anos da Universidade, ela acredita que iniciativas desse tipo se tornam mais evidentes. Ainda assim, há um bom caminho a se trilhar até que o investimento de tempo, dinheiro e espaço físico na preservação desses materiais se torne algo sistêmico.

\section{IMAGENS DO PASSADO}

O Instituto de Psicologia (IP) é uma das unidades da USP que têm uma tradição de preservação e valorização de sua própria história. Desde 2001, quando comemorou seus 30 anos de existência, o Instituto possui um Centro de Memória que tem como objetivo organizar, preservar e divulgar documentos e materiais relacionados à história da psicologia na USP. Seu acervo contém memoriais de professores, que datam da inauguração do IP em 1970, bem como fotografias, fitas, CDs, DVDs e relatórios anuais de atividades. Por meio dos editais de 2012, o Centro de Memória pôde dispor de recursos para organizar e digitalizar o seu acervo fotográfico, graças ao projeto de Maria Marta Nascimento, bibliotecária do Instituto.

Esse acervo contém um conjunto de imagens bastante impressionantes: desde fotos de docentes do IP, como o professor Dante Moreira Leite, patrono da biblioteca do Instituto, até imagens do Laboratório de Pedagogia Experimental, de 1914, instituição que pode ser considerada uma espécie de embrião tanto do Instituto de Psicologia quanto da Faculdade de Educação (FE-USP).

O projeto prevê, também, a criação de uma base de dados para catalogar essas imagens e disponibilizá-las na internet. Algumas delas já estão disponíveis no site www.usp.br/acervofotografico.

Outras imagens que Marta destaca são as fotografias do palacete da Alameda Glete, um imenso 

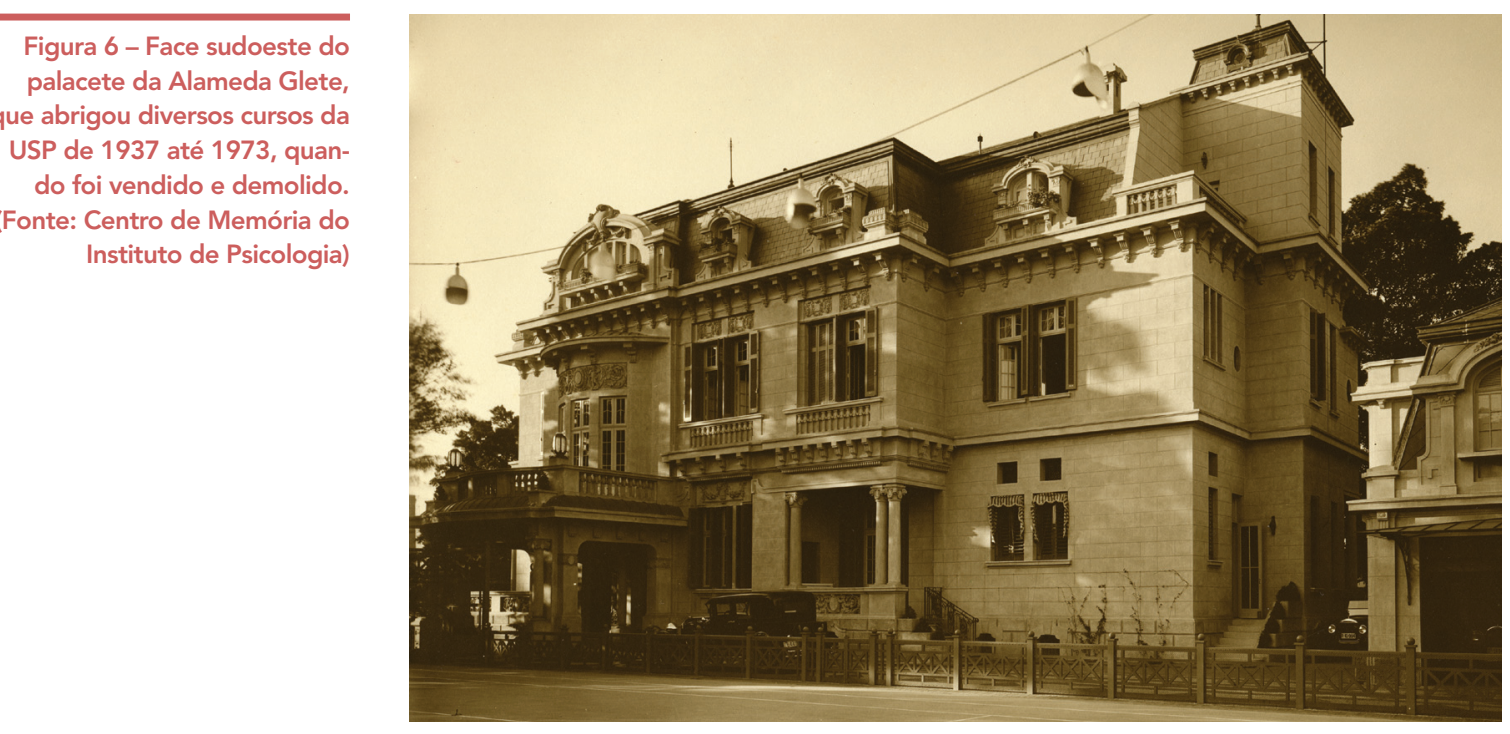

casarão onde ocorriam aulas de psicologia experimental nas décadas de 40 e 50 do século passado, num momento em que a psicologia ainda estava se configurando como curso de graduação na USP (o curso só iniciou seu funcionamento em 1957, e o Instituto de Psicologia foi fundado apenas em 1969). O fato de esse palacete já ter sido demolido torna ainda mais importante a preservação dessas imagens.

É o mesmo caso do bloco "B2", um edifício do IP onde estava localizada a biblioteca e que precisou ser demolido por conta de problemas estruturais. As fotos que o Centro de Memória tem desse edifício mostram também diversas pichações em seus muros. Segundo Marta, as fotografias foram tiradas por um professor do Instituto, que queria retratar e preservar aquele momento do bloco.

$\mathrm{Na}$ avaliação da bibliotecária, o IP tem bastante carinho pela sua história. "Existe uma preocupação grande por parte dos dirigentes do Instituto e dos professores, que sempre colaboram bastante com essa questão da história", diz. Segundo ela, "hoje, na USP, está se pensando muito nisso. A gente vê que tem esse interesse em resgatar e preservar a memória para o futuro".

No entanto, esse processo ainda encontra alguns obstáculos, particularmente devido à burocracia envolvida na contratação de serviços.
Segundo Marta, os serviços de restauração devem ser contratados pelo menor preço disponível - o que muitas vezes corresponde a um serviço de menor qualidade. E, no caso da restauração de documentos antigos, a contratação de um serviço inadequado pode comprometer a própria imagem ou documento a ser restaurado.

\section{COMO ERA, COMO É}

A professora Cristina Costa, presidente da Comissão de Pesquisa da Escola de Comunicações e Artes (ECA-USP), faz uma crítica semelhante: "É muita burocracia. É um problema sério, porque estamos ficando cartoriais demais".

A docente coordena o projeto Memórias da ECA: 50 anos. Ela vinha trabalhando em uma pesquisa bastante extensa sobre a censura, tanto na Era Vargas quanto na ditadura militar, quando foi abordada pelo então diretor da ECA, professor Mauro Wilton. Ele lhe sugeriu a realização de um trabalho que recuperasse a memória da Escola de Comunicações e Artes, por conta da aproximação do aniversário de 50 anos da Escola, que ocorrerá em 2016. Através dos editais, Cristina viu uma possibilidade de realizar esse projeto. 
Nesse trabalho, Cristina entrevistou antigos alunos e professores da ECA, como o cartunista Laerte Coutinho e o teatrólogo Jacob Guinsburg. Seus depoimentos foram gravados e serão, posteriormente, disponibilizados na internet. Cada um deles teve a oportunidade de contar sua relação com a Escola, as histórias marcantes de sua passagem pela Universidade, e de refletir sobre como esse percurso contribuiu para suas vivências acadêmica e pessoal.

Ao relatar sua vivência na Universidade, os entrevistados acabam por deixar também, àqueles que ouvem seus depoimentos, a noção nem sempre presente de que a ECA já foi muito diferente do que é hoje: já se chamou Escola de Comunicações Culturais, ficava em um só edifício e tinha cursos separados para Cinema e Radio \& TV, por exemplo. "Muitos professores falam sobre o cotidiano, e alguns deles se emocionam ao se lembrar, é muito bom”, conta Cristina.

Ao longo do projeto, alguns temas comuns a todos os entrevistados começaram a aparecer: "Um deles é a ditadura. A memória histórica da ditadura militar tem um peso muito grande". Segundo ela, havia uma espécie de "guerra fria" naquela época, uma dicotomia que opunha os que lutavam contra o regime ditatorial e os que se submetiam a ele. "Então há uma preocupação muito grande, em alguns entrevistados, de apontar quem era quem". Outra questão que apareceu com frequência nos depoimentos foi a separação entre artes e comunicações. "Como é um tema que se discute novamente hoje em dia, todos falam, a favor ou contra. As opiniões se dividem sobre isso".

Além dos depoimentos, o grupo de trabalho também está digitalizando os memoriais dos professores e buscando documentos, imagens e filmes antigos, desde escritos oficiais ou institucionais até produções dos próprios alunos desde a criação da ECA. Esse primeiro momento do projeto pretende juntar esse material e, posteriormente, disponibilizá-lo na internet. O objetivo final, porém, é construir um site que seja ao mesmo tempo "difusor e constituidor dessa memória”, nas palavras da docente. Nele, será possível que qualquer aluno, professor ou funcionário que trabalhe na ECA deixe registrado seu depoimento, além de poder acrescentar imagens e vídeos. "A ideia é que cada pessoa que passou pela ECA possa deixar seu registro", diz.

Segundo Cristina, a ECA já tem uma tradição de valorizar a própria memória. Ela cita, por exemplo, o trabalho de professores como Ecléa Bosi, que ministra cursos sobre o resgate da memória, e Cremilda Medina, do Departamento de Jornalismo, que desenvolveu um projeto cujo objetivo era resgatar a memória dos bairros de São Paulo. "Eu diria que é uma vertente que já existe há muitos anos”.

\section{O FUTURO DA MEMÓRIA}

A importância de iniciativas desse tipo, segundo Cristina, é enorme. "Eu acho que é muito saudável que a USP esteja querendo construir a sua história. É muito importante lembrar a história para não repetir os erros".

Embora considere que a USP, se comparada a outras instituições de ensino superior da Europa, por exemplo, é ainda muito jovem, ela reconhece que 80 anos são um marco importante nessa história: "Acho que esse é o momento em que estamos percebendo que estamos nos tornando históricos".

O diretor do CPC já enxerga muitas possibilidades de aprofundar essa iniciativa, da qual ele acredita que os editais representam uma primeira etapa. "Eu tenho a impressão que um salto a ser dado no futuro seria ultrapassar essa própria situação de edital, que pode ser sustentado ano após ano, mas que pode ser interrompido sem qualquer constrangimento", opina. Seria interessante, em sua opinião, que a Universidade "investisse em uma política permanente de congregação dessas pesquisas, dessas memórias" para que esses processos de recuperação e revisão do passado passassem a fazer parte “da própria vida da Universidade”.

O professor Lira vê, também, oportunidades de ampliar esses editais, de forma a realizar ainda melhor os objetivos de extensão universitária no campo do patrimônio cultural. Segundo ele, "uma área 
que me parece ainda pouco considerada pela USP é a área de conhecimentos tradicionais". "Nós, a Universidade, os acadêmicos, tradicionalmente nos afirmamos pela negação das culturas tradicionais (...), [mas] cada vez mais as ciências, e não só as humanidades, estão se colocando o desafio de pensar a relação entre essas linguagens, objetivos e práticas e as práticas que comumente definimos como científica”.

"Hoje, um dos grandes desafios da Universidade é essa capacidade dela se abrir para o novo, abrir-se para o outro", afirma o professor. "Essa capacidade de criar campos de trocas e contaminações, de se aproximar de outras realidades, isso é visto como algo a ser conquistado, tal o grau de isolamento que as universidades foram construindo em sua história”. Para Lira, essa aproximação é algo essencial para o futuro da USP: "Não há dúvida de que a Universidade tem muito a oferecer à sociedade, mas se a sociedade não se der conta da importância dessa instituição não só para resolver problemas, mas também para propor novos problemas e enfoques, dificilmente a Universidade sobreviverá", diz ele.

Quanto aos editais, o professor opina: "há um germe plantado, e eu acho que isso é um resultado inestimável". Ele vê nessa construção de uma "política de memória” da Universidade um processo crucial: "Hoje, a Universidade está olhando para si de outra maneira, em grande parte graças a essa mobilização de talentos, conhecimentos e sensibilidades de professores, funcionários e estudantes em torno dessas questões".

A professora Cristina considera difícil a formação de uma memória única e monolítica da Universidade, "porque nós somos muito grandes e diversificados, muito díspares”. No entanto, ela também ressalta a necessidade de que a USP desenvolva uma "cultura da memória, que valorize as iniciativas locais”. "Nós somos a nossa memória. Quando você consegue integrar a sua memória a uma memória coletiva, a sensação é muito boa. Você se sente parte, e fazendo parte você se sente mais indivíduo”.
GUSTAVO SUMARES graduando em Jornalismo da Escola de Comunicações e Artes da Universidade de São Paulo (ECA-USP) e repórter da Revista Cultura e Extensão USP - e-mail: gsumares@gmail.com

\section{MEMÓRIA USP}

Por ocasião do aniversário de 80 anos da USP, o Museu de Ciências lançou o site do projeto Memória USP, que tem como objetivo reunir em uma só plataforma virtual informações sobre acontecimentos, locais e pessoas marcantes da história da Universidade. $\mathrm{O}$ endereço eletrônico é mc.prceu. usp.br/memoria.

O site possui uma linha do tempo que, além de pontuar os principais eventos que marcaram a história da USP, inclui informações específicas sobre as várias unidades de ensino e órgãos da Universidade.

Além de dados gerais sobre o passado da USP, o site contém também acervos documentais e fotográficos das unidades, disponíveis para uso segundo a licença Creative Commons. 